\title{
Commentary: For the pumps they are a-changin'
}

\author{
Bryan A. Whitson, MD, PhD
}

In 2019, we are solidly in the era of centrifugal-flow left ventricular assist devices (LVADs) in both the destination therapy and bridge to transplant as well as potentially bridge-to-decision patients. Although many a pundit could argue the respective merits of this centrifugal pump versus that centrifugal pump, we may never have a true head-tohead comparison from which to draw meaningful, absolute conclusions. What we do know is that previous-generation pumps have had a propensity for pump thrombosis and, to a lesser degree, current-generation pumps can as well. What we strive for then are approaches to managing the population of older pumps currently in patients and those future patients who may develop pump thrombosis.

In this edition of the Journal, Barac and colleagues ${ }^{1}$ from Duke University report their experience on the exchange of HeartMate II and HeartWare Ventricular Assist Device (ie, HVAD) pumps to HeartMate 3. Although there are some limitations due to the sample size, this is arguably one of the world's largest experiences with this conversion. What we see is that the experience is a varied as the patients we manage-different pump types, different numbers of exchanges, different surgical approaches, and different pre-existing comorbidities and disease processes. We see that there is a small subset of patients who require multiple pump exchanges and this approach to pump exchanges should be addressed in a patient-by-patient basis. Although there is heterogeneity in the presentation and technique of pump exchange depending on the pump and body habitus, the structured approach to management and surgical technique is evident.

\footnotetext{
From the Division of Cardiac Surgery, Department of Surgery, The Ohio State University Medical Center, Columbus, Ohio.

Disclosures: Author has nothing to disclose with regard to commercial support.

Received for publication Dec 3, 2019; revisions received Dec 3, 2019; accepted for publication Dec 3, 2019; available ahead of print Dec 23, 2019.

Address for reprints: Bryan A. Whitson, MD, PhD, Division of Cardiac Surgery, Department of Surgery, The Ohio State University Medical Center, N-816 Doan Hall, 410 W. 10th Ave, Columbus, OH 43210 (E-mail: bryan.whitson@osumc. edu).

J Thorac Cardiovasc Surg 2020;160:140

0022-5223/\$36.00

Copyright (c) 2019 by The American Association for Thoracic Surgery

https://doi.org/10.1016/j.jtcvs.2019.12.019
}

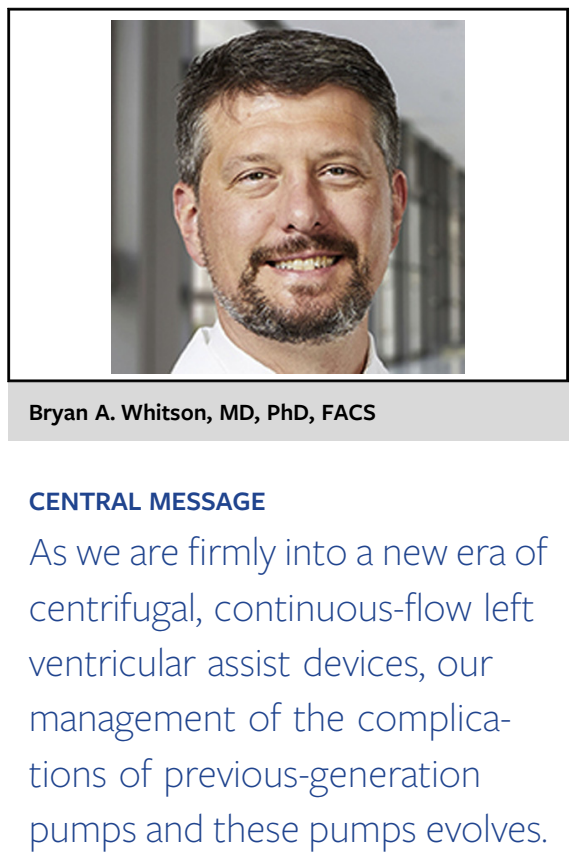

In the end, Barac and colleagues have provided us a structured approach and recommendation to addressing those patients with LVAD remaining with HeartMate II pumps in service and in our newer generation of centrifugal-flow LVADs in need of LVAD exchange for definitive pump-thrombosis management. Working to expand these processes across centers will undoubtedly help to systematize their management and improve outcomes.

\section{Reference}

1. Barac YD, Wojnarski CM, Junpaparp P, Jawitz OK, Billard H, Daneshmand MA, et al. Early outcomes with durable left ventricular assist device replacement using the HeartMate 3. J Thorac Cardiovasc Surg. 2020;160:132-9.e1. 